\title{
Electrochemically-induced Reduction of Nitrate in Aqueous Solution
}

\author{
Lj. Rajic * D. Berroa, S.Gregor, S. Elbakri, M.MacNeil, A. N. Alshawabkeh \\ Department of Civil and Environmental Engineering, Northeastern University, 400 Snell Engineering, \\ 360 Huntington Avenue, Boston, MA 02115, United States \\ *E-mail: 1.rajic@neu.edu
}

doi: $10.20964 / 2017.07 .38$

Received: 14 February 2017 / Accepted: 5 April 2017 / Published: 12 June 2017

\begin{abstract}
In this study, we evaluated the removal of nitrate from synthetic groundwater by a cathode followed by an anode electrode sequence in the electrochemical flow-through reactor. We also tested the feasibility of the applied electrode sequence to minimize the production of ammonia during the nitrate reduction. The performance of monometallic $\mathrm{Fe}, \mathrm{Cu}, \mathrm{Ni}$, and carbon foam cathodes was tested under different current intensities, flow rates/regimes, and the presence of $\mathrm{Pd}$ and $\mathrm{Ag}$ electrode coating. With the use of monometallic Fe and an increase in current intensity from $60 \mathrm{~mA}$ to $120 \mathrm{~mA}$, the nitrate removal rate increased from $7.6 \%$ to $25.0 \%$, but values above $120 \mathrm{~mA}$ caused a decrease in removal due to excessive gas formation at the electrodes. Among tested materials, monometallic Fe foam cathode showed the highest nitrates removal rate, which further increased from $25.0 \%$ to $39.8 \%$ in the presence of Pd catalyst. In addition, the circulation under $3 \mathrm{~mL} \mathrm{~min}^{-1}$ elevated the nitrate removal by $33 \%$, and the final nitrate concentration fell below the maximum contaminant level of $10 \mathrm{mg} \mathrm{L}^{-1}$ nitrate-nitrogen $\left(\mathrm{NO}_{3}-\mathrm{N}\right)$. During the treatment, the yield of ammonia production after the cathode was $92 \pm 4 \%$, while after the anode $\left(\mathrm{Ti} / \mathrm{IrO}_{2} / \mathrm{Ta}_{2} \mathrm{O}_{5}\right)$, the amount of ammonia significantly declined to $50 \%$. The results proved that flow-through, undivided electrochemical systems with Fe cathodes can be used to remove nitrate from groundwater to safe levels with the possibility of simultaneously controlling the generation of ammonia via anodic processes.
\end{abstract}

Keywords: electrochemical; nitrates; ammonia; groundwater; cathode.

\section{$\underline{\text { FULL TEXT }}$}

(C) 2017 The Authors. Published by ESG (www.electrochemsci.org). This article is an open access article distributed under the terms and conditions of the Creative Commons Attribution license (http://creativecommons.org/licenses/by/4.0/). 